\title{
O LULISMO CONFRONTADO NAS RUAS: PROJETO POLÍTICO E CICLO DE PROTESTO NO BRASIL (2013-2017)
}

\author{
Lulism confronted on the streets: an perspective of the current cycle of \\ protest in Brazil (2013-2017)
}

\begin{abstract}
Cláudio André de Souza
Mestre e Doutor em Ciências Sociais pela Universidade

Federal da Bahia. Professor de Ciência Política na Universidade da Integração Internacional da Lusofonia Afro-Brasileira (UNILAB), Campus dos Malês (BA)
\end{abstract}

\author{
Informações do artigo \\ Recebido em 30/10/2017 \\ Aceito em 05/12/2017
}

\begin{abstract}
Resumo
Este trabalho tem o propósito de estimular o debate conjuntural sobre a política brasileira, considerando a existência de uma crise do lulismo enquanto fenômeno de representação política que culminou com o impeachment da presidenta Dilma Rousseff (PT) em agosto de 2016, a partir de vários fatores internos levados à frente enquanto articulações de bastidores no âmbito das instituições - e fatores externos - através da realização de um conjunto de mobilizações de segmentos sociais de maior renda e escolaridade das grandes cidades brasileiras, levando a consequências mais amplas que o desfecho do impeachment diante de um ativismo societário que tende a gerar impactos de longo prazo. Sendo assim, busca-se apresentar o conceito de ciclo de protesto como instrumental analítico para interpretar uma "virada conservadora" na sociedade civil brasileira em torno de um projeto político neoliberal de ampla consequência para a construção democrática no país. Diferente das análises de caráter institucional predominantes na ciência política, o objetivo deste artigo reside na aproximação à perspectiva de compreender a democracia para além da ambiência eleitoral.

Palavras-chave: Iulismo; protesto; conjuntura.
\end{abstract}

\section{Introdução}

Quando André Singer (2012) lançou Os sentidos do lulismo, definindo lulismo enquanto fenômeno de realinhamento eleitoral, pouco se tinha disponível nas ciências sociais de material bibliográfico de síntese intelectual do que estava acontecendo no Brasil desde a primeira década dos anos 2000. Para o autor, a escolha por dar aos pobres sem tirar dos ricos teve como objetivo promover um projeto de reformismo fraco, sem arriscar a sobrevivência do pacto conservador. O lulismo como fenômeno advém do realinhamento eleitoral das camadas mais pobres do eleitorado, que passam a apoiar Lula nas eleições de 2006, e o voto dos mais ricos migra para o PSDB.

Uma das chaves explicativas do lulismo que interessa nesse momento é que há um rebaixamento do papel das classes, arbitrando interesses orientados para somente superar 
a pobreza, em substituição às desigualdades. Desse modo, o projeto lulista resumiu-se, até 2014, a representar os mais pobres diante de uma narrativa de confronto com os mais ricos. Se as alianças políticas estavam sustentadas pelo propósito da governabilidade, as clivagens organizadas na sociedade mereciam de Singer um olhar mais preocupado em perceber as nuances dos impactos do lulismo nos movimentos sociais. Não obstante, isso pouco impõe limites ao alcance dos resultados obtidos pelo autor.

Aqui entendemos, para além do que analisara Singer, o lulismo também como um fenômeno de representação política, observado por meio do apoio eleitoral e, ainda mais, em torno das disputas no âmbito da cultura e da política, que envolvem a afirmação dos projetos políticos como um instrumental analítico capaz de balizar as relações entre a sociedade civil e a sociedade política (DAGNINO; OLVERA; PANFICHI, 2006), sendo imprescindível estudar a democracia a partir da ótica societária.

Um primeiro ponto crucial para entendermos a crise política na qual vive o lulismo tem como ponto de partida os acontecimentos na conjuntura econômica, analisados por Singer (2015) em um artigo, lançado no final de 2015, sobre as escolhas políticas que levaram à tentativa da presidenta Dilma Rousseff (PT) de mudar as orientações da economia, buscando defender os interesses desenvolvimentistas, que, porém, se viram derrotados com a rearticulação dos capitalistas, que se colocavam em posição de divergência sobre o caráter intervencionista do governo, selando os contornos da crise iniciada após as eleições de 2014, quando, após eleito, o governo resolveu ceder e voltar atrás nos seus interesses desenvolvimentistas, favorecendo o bloco rentista enquanto fração da classe burguesa. É inevitável perceber as tensões do lulismo na conformação da arbitragem de interesses opostos, enquanto um signo do lulismo (SINGER, 2012). Para o autor,

\footnotetext{
ao cutucar onças, a presidente deveria ter considerado os instrumentos que teria à mão para reagir quando viesse o bote do contra-ataque. Sem planejamento político, o ensaio desenvolvimentista abriu um vácuo sob os próprios pés e acabou por provocar a mais séria crise do lulismo quando a reação burguesa unificada em favor do retorno neoliberal tornou-se incontrastável. Até por não haver, na sociedade, quem enxergasse a necessidade de contrastá-la (SINGER, 2015, p. 71).
}

Singer ressalta que a defesa desse ensaio desenvolvimentista (crítico ao bloco rentista e a favor da burguesia produtivista e industrial) necessitaria da intensa mobilização dos trabalhadores, criando um maior nível de politização sobre as questões econômicas diante da estratégia de enfrentamento a partes da própria coalizão de governo. Nesse período, as principais mobilizações, encetadas de forma relevante na conjuntura, colocaram o lulismo 
"contra a parede". As manifestações de junho de 2013 tiveram como grande parte o público de jovens urbanos de classe média, preocupados em criticar a política e os políticos, em especial, cobrando uma maior qualidade dos serviços públicos, conforme aponta Renato Janine Ribeiro (2014).

As críticas direcionadas à Copa de 2014 pareceram pertinentes, já que, além dos altos gastos públicos para a realização do evento, os protestos estavam situados na ineficácia do sistema político em produzir resultados "republicanos" diante do tamanho do agravamento da corrupção na política. A cobrança de serviços públicos mais eficientes fazia todo sentido para a vida de milhares de pessoas a viver nas grandes metrópoles, trazendo às ruas, nas jornadas de junho de 2013, um divórcio com governo e partidos políticos, estabelecendo uma crise de representação que ultrapassa o espectro político-eleitoral do lulismo.

Essa indignação atingiu a todos em 2013, mas, especialmente, a avaliação do governo da presidenta Dilma Rousseff (ver Figura 1), despencando a popularidade do seu mandato, somando-se às dificuldades de governabilidade engendradas nas tensões estabelecidas no encaminhamento das agendas do governo dentro e fora da arena parlamentar. Talvez um dos equívocos desse momento tenha sido o governo não ter "compartilhado" as críticas ao sistema político com todos os atores políticos (partidos, parlamentares, governadores, prefeitos, etc.) e ter produzido pouco diálogo com a classe média mobilizada e conformada por cidadãos difusos nas ruas. Este "abandono" da classe média já tinha sido uma estratégia do PT e dos partidos de esquerda governistas ao estigmatizar as críticas públicas ao caso do mensalão como uma mera e "ilegítima" conspiração das elites, algo que o próprio André Singer notou, nas suas análises, percebendo que os estratos de renda (pesquisa de intenção de voto, Ibope) estavam socialmente polarizados em 2006, com o candidato da oposição Geraldo Alckmin (PSDB) contando com os votos dos mais ricos.

De algum modo, as manifestações contra o Partido dos Trabalhadores (PT) em 2015 se estabelecem como uma continuidade do ciclo de protestos iniciado em 2013, mas com milhares de cidadãos canalizando as suas desconfianças e insatisfações nas instituições exclusivamente em direção ao petismo e ao lulismo. A construção dos protestos após a reeleição de Dilma se deu em torno do confronto aberto com o governo e o seu principal partido, amplificando uma crítica "seletiva" ao fenômeno da corrupção, embora, já naquele período, a Operação Lava Jato tivesse apontado para a existência de um suposto esquema mais amplo de corrupção envolvendo o sistema político. 
Figura 1 - Gráfico avaliação de governo da presidente Dilma Rousseff (2011-2015)

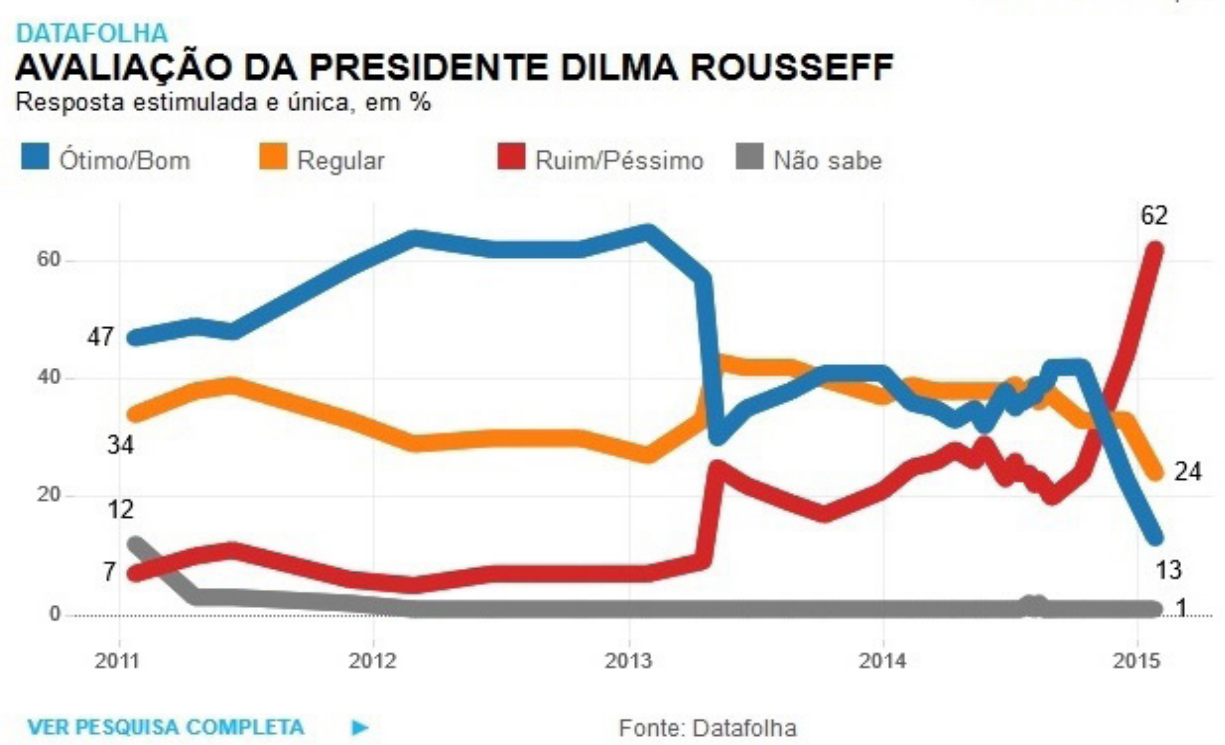

Fonte: Site Pragmatismo Político, 2015.

Esse trabalho tem um caráter despretensioso em relação aos aspectos que envolvem a crise política presente, até porque as tensões que envolvem o momento político atual não tiveram um fim com o desfecho do impeachment e podem atravessar as eleições presidenciais de 2018.

O objetivo central desse artigo é apresentar um panorama com relação ao perfil das manifestações de 2015 contra o governo Dilma e o PT, e de que forma elas reforçaram a crise política que tem abatido o lulismo desde os desdobramentos das eleições de 2014. Desse modo, a estrutura deste trabalho envolve um primeira parte sobre o perfil das manifestações contra o PT e uma segunda parte envolvendo a atuação dos movimentos sociais contra o "golpe" nesse período, assim como uma leitura sobre os principais fatos da conjuntura atual. O argumento central sustentado aqui é que dificilmente haverá, a curto prazo, uma derrocada final do lulismo no âmbito da representação política dos segmentos mais pobres da população, mas trata-se de um jogo aberto neste momento político atual, marcado por incertezas no âmbito da atuação dos movimentos sociais, partidos e forças governistas pósimpeachment ${ }^{1}$. Sugerimos, nesse momento, que a esquerda está a construir estratégias em torno de um pós-lulismo, buscando reverter a intensa conciliação de classes nos governos

1 As condenações em andamento contra o ex-presidente Lula ligadas à Operação Lava Jato deixam em aberto a sua presença nas eleições de 2018 , pondo em teste o lulismo e o petismo enquanto representantes eleitorais dos trabalhadores. 
Lula e Dilma. De uma maneira geral, a ascensão do lulismo, conforme as análises de André Singer, é um marco estratégico que está posto na experiência mais exitosa da esquerda, que, na transição para a democracia, foram canalizadas para a atuação do PT. É importante considerar que,

beneficiado pelo boom de commodities, o reformismo fraco dos governos petistas, apesar de não romper de maneira radical com o padrão estabelecido desde a Nova República, retomou a partir de 2003, de maneira diluída, aspirações derrotadas em 1964. Conseguiu reduzir desigualdades, sobretudo por meio da política de aumento do salário mínimo e de expansão do emprego, mas também mediante programas específicos, dos quais se poderia destacar o Bolsa Família, o apoio à pequena agricultura, o subsídio à moradia popular e a facilitação do acesso à universidade às camadas de baixa renda, entre outros. Ao mesmo tempo, na medida em que buscou avançar sem fazer transformações estruturais - seja no plano dos direitos, seja no da economia ou da ideologia -, a segunda experiência desenvolvimentista caracterizou-se pela extrema ambiguidade (SINGER; LOUREIRO, 2016, p. 12)².

\section{Eclosão da crise política atual: perfil dos protestos e radicalização do antipetismo}

É difícil, e quase mágico, situar todos os fatores que levaram à eclosão da crise política atual, contudo, vemos como necessário ter como "marco fundante" o peso da deslegitimação do processo eleitoral, promovida pelo PSDB ainda durante as eleições de 2014, algo que balizou os segmentos da sociedade civil a se mobilizarem denunciando uma suposta falta de condições da presidente Dilma para governar.

Ainda durante a campanha, o candidato Aécio Neves (PSDB) já falava na falta de condições morais da presidenta Dilma para pleitear um segundo mandato, conforme reportagem de Daniel Leite do O Globo, publicada em 13/09/201433, por conta dos escândalos decorrentes das investigações promovidas pela Operação Lava Jato. Garantida a vitória no segundo turno de 2014, a presidenta Dilma passou a conviver com uma forte oposição ao seu governo, agora ampliada pelo aumento dos oposicionistas dentro do parlamento, cuja consequência foi a eleição de deputados de partidos aliados, mas que apoiaram a oposição nas eleições. Também teve no seu encalço uma intensa oposição na sociedade civil, que foi bastante mobilizada desde a campanha presidencial e com forte presença nas redes sociais.

\footnotetext{
SINGER, André; LOUREIRO, Isabel. As contradições do lulismo: a que ponto chegamos. São Paulo: Boitempo, 2016.

3 LEITE, Daniel. Aécio Neves diz que Dilma não tem condições morais de pleitear segundo mandato. O Globo, 13 set. 2014. Disponível em: <http://oglobo.globo.com/brasil/aecio-neves-diz-que-dilma-nao-tem-condicoesmorais-de-pleitear-segundo-mandato-13927985>. Acesso em: 27 ago. 2016
} 
As mobilizações, organizadas no calor da vitória presidencial no segundo turno de 2014, lembraram a indignação com o governo e o conjunto do sistema político como algo produzido pelas manifestações de junho de 2013. Para Romão (2013), tais manifestações mostraram o quanto o governo foi incapaz de debater agendas com a sociedade civil e estes segmentos mobilizados, ocasionando um declínio dos índices de aprovação do governo (Datafolha): entre abril de 2012 e março de 2013, a aprovação da presidente Dilma oscilava entre os 62 e 65 pontos percentuais, sendo, em novembro de 2013 , somente $36 \%$.

Vale registrar que a queda do governo Dilma também resultou de equívocos que já se mostraram evidentes no mesmo dia da sua reeleição. Após a sua reeleição ser consagrada nas urnas em 26/10/2014, a ex-presidente subiu ao palco do auditório de um hotel em Brasília acenando para uma "base comum de entendimento" com a oposição, afirmando, em um tom firme, que "em lugar de ampliar divergências, de criar um fosso, tenho forte esperança de que a energia mobilizadora tenha preparado um bom terreno para a construção de pontes", disse a presidenta reeleita. Em outro trecho do seu discurso ${ }^{4}$, ela fez um chamamento à paz e à união, clamando pela abertura ao diálogo como o primeiro compromisso do segundo mandato. Este recado da presidenta não foi ingênuo, mas estava ali um aceno aos eleitores, já que os seus auxiliares diretos já sabiam que havia um clima tensionado na sociedade civil de que o governo não deveria tomar posse. A estratégia seria razoável se não fosse este diálogo com a oposição vazio de reciprocidade, em razão da pouca habilidade e articulação do Planalto em criar fatos políticos concretos nesse diálogo com as forças da oposição e que buscassem isolar as articulações do candidato Aécio Neves em gerar um "terceiro turno". Este desiderato já estava nítido quando o PSDB protocolou, poucos dias após a votação do segundo turno, um pedido de recontagem dos votos ${ }^{5}$, colocando em xeque o sistema eleitoral e a legitimidade do resultado auferido nas urnas. Alguns meses depois, a articulação em torno da eleição de Eduardo Cunha à presidência da Câmara carregaria o mesmo objetivo: minar a governabilidade do Planalto.

Para piorar, faltou ao governo timing em mapear as forças internas da sua base aliada em torno de uma governabilidade que não ficasse restrita às lideranças parlamentares, mas que tivesse, no primeiro escalão, nomes e lideranças sociais e políticas fora do cálculo

4 Assista ao discurso na íntegra no link: <https://tvuol.uol.com.br/video/em-discurso-de-vitoria-dilma-pedeuniao-e-diz-que-ira-priorizar-dialogo-04020E1A3960D4915326>

5 Matériacompletanolink:<http://politica.estadao.com.br/noticias/geral,psdb-de-aecio-neves-pede-auditoria -na-votacao,1585755> 
partidário dentro da arena parlamentar, o que foi confirmado com a eleição de Eduardo Cunha. Teria sido mais prudente compor um ministério com "notáveis", que pudessem agregar representatividade na sociedade civil, conquistando mais força social frente ao golpismo em marcha. O que se viu foi um equívoco de leitura política: um ministério composto com a chancela dos líderes partidários que prometeram votos no congresso sem nenhuma condição (ou intenção) de cumprir com o acordo, sendo que o governo não percebera que avançava em tempo real a articulação do PSDB em construir um clima de "caos político" nos bastidores. As manifestações nas ruas foram a cereja do bolo para a oposição, que, a esta altura, se valia do clamor das ruas para pavimentar a narrativa de que não havia como o governo Dilma continuar a existir.

Se, por um lado, as manifestações de junho de 2013 estavam presentes em 2015, por meio da indignação com o sistema político e a corrupção, além das críticas a um suposto fracasso da economia brasileira, por outro, a grande novidade das manifestações de março daquele ano estava ligada às críticas radicalizadas ao PT e ao Governo Dilma. Os protestos antipetistas se iniciaram antes mesmo da posse da presidenta reeleita. Em 06/12/2014, segundo o site UOL, manifestantes se reuniram

para pedir o impeachment da presidente reeleita Dilma Rousseff. Segundo a assessoria de imprensa da Polícia Militar, a concentração do protesto no Vão Livre do Masp, na avenida Paulista, reuniu cerca de 800 pessoas. O número de manifestantes, no entanto, aumentou ao longo da caminhada"6.

O antipetismo constituído nesse cenário apontava, sobretudo, para um caráter programático, para além de uma perspectiva reativa por meio do ódio ao PT e à esquerda, significava a negação de um determinado projeto político no âmbito da representação eleitoral, definido como um "[...] conjunto de crenças, interesses, concepções de mundo, representações do que deve ser a vida em sociedade, que orientam a ação política dos diferentes sujeitos" (DAGNINO; OLVERA; PANFICHI, 2006, p. 38). Esta definição dos autores do conceito de projeto político caracteriza muito bem o embate aberto a partir da reeleição da presidenta Dilma, ao evidenciar que a disputa ultrapassara os contornos institucionais de competição política para assumir um embate mais amplo e complexo nos terrenos da sociedade civil e da sociedade política. A disputa em torno de projetos políticos está em

\footnotetext{
6 Matéria completa nos links a seguir: <https://eleicoes.vol.com.br/2014/album/2014/12/06/manifestantefazem-protesto-contra-dilma.htm> Acesso em 25/out. 2017; <http://www1.folha.vol.com.br/poder/2014 12/155880g-manifestantes-em-sp-protestam-contra-dilma-e-escandalo-na-petrobras.shtml> Acesso em 25/out. 2017
} 
aberto na sociedade civil e não cessará com as manobras disponíveis no campo institucional do presidencialismo de coalizão. Para a esquerda, o grande desafio é converter-se à tese de que parte dos conflitos inerentes à sociedade brasileira ganharam contornos acima do que pode ser oferecido pelo lulismo ou a sua reedição nas próximas eleições presidenciais. Para André Singer, na sua coluna na Folha de São Paulo publicada em 14/05/2016 (página A2),

com a derrubada do lulismo diante do impeachment, interrompe-se mais uma vez a tentativa - no fundo a mesma de Getúlio Vargas — de integrar os pobres por meio de uma extensa conciliação de classe. Venceu de novo a forte resistência nacional a qualquer tipo de mudança verdadeiramente civilizatória. Mesmo a mais moderada e conciliadora.

O dilema atual do PT se enquadra na questão posta em entrevista recente do líder do movimento dos sem-teto Guilherme Boulos, publicada no livro A crise das esquerdas (Civilização Brasileira, 2017),

\begin{abstract}
no caso brasileiro, a crise desnudou uma contradição e colocou o tema de que não é mais possível que haja pequenos avanços sem reformas. O que estava em jogo era uma política de inclusão de programas sociais por manejo orçamentário, sem alterar a estrutura do Estado, sem mexer essencialmente em temas distributivos na sociedade. Isso chega ao teto quando a arrecadação passa a crescer menos por conta da crise econômica. E aí se coloca essa encruzilhada: ou se avança em temas centrais, como o tributário e o da dívida pública, ou então se realiza um retrocesso, uma regressão social no país, com aplicação de políticas de austeridade. No caso de alguns governos bolivarianos, o dilema é outro: em alguns desses países, houve reformas importantes, estruturais, as que reivindicamos aqui. Entretanto, lá bateuse num teto em que, também por conta da crise, não foi possível continuar um programa de reformas sem rupturas estruturais. No caso da Venezuela, por causa da dependência do petróleo, evidencia-se o quanto a crise incide no processo. Mais da metade do financiamento do Estado venezuelano gira em torno do petróleo. $\mathrm{O}$ barril custava 100 dólares há pouco tempo e caiu para menos de 40 dólares, embora hoje haja uma reação positiva. Numa situação como essa, qualquer processo político sofreria uma crise brutal. Os nossos países latino-americanos são ainda essencialmente dependentes de uma pauta primária: gás, produtos agrícolas, minérios, etc. É sabido que um dos efeitos fortes da crise foi a redução brutal do preço das commodities no mercado internacional. As condições econômicas reduziram a margem de manobra dos governos na América Latina e foram circunscrevendo limites que não são iguais para todos os países. No caso brasileiro, o limite de não poder mais ter avanços sem reformas (p. 134-135).
\end{abstract}

A radicalização do antipetismo tem como principal característica a continuidade do ciclo de protesto, aberto em 2013, apresentando como principal agenda para mobilização as críticas ao Governo Dilma e ao PT como se fossem a mesma coisa. É emblemática a criação do Movimento Brasil Livre (MBL) e do Revoltados Online como espaços virtuais de mobilização, mas que se tornaram entidades baseadas na criação de fóruns e espaços "reais" de articulação política, aproximando-se, em todo o Brasil, de redes de entidades engajadas em posições 
antipetistas, como é o caso, por exemplo, das associações que representam os médicos, que se situam em uma forte oposição ao governo petista desde 2013 , nos embates referentes à contratação de médicos estrangeiros para trabalhar no Programa Mais Médicos, tal programa como sendo a política mais bem sucedida em diálogo com as jornadas de junho de $2013^{7}$.

De fato, conforme Espiñeira e Matheus (2015), aquilo que aparentava ser difuso nos discursos de alguns manifestantes de 2013 tornou-se presente nos discursos das mobilizações de 2015 , enquanto uma reação organizada de grupos da direita para a retomada do poder político. Romão (2015) ressalta que a agenda de parte dos grupos à esquerda - os Comitês Populares da Copa - dividiu o protagonismo destas mobilizações com os manifestantes convocados pela internet nas páginas de grupos de direita críticos ao Governo Dilma e ao PT.

As manifestações produzidas ao longo de 2015 tiveram contorno de indignação com o PT, mas apontavam para críticas referente à parte do projeto político do lulismo que estava mais próxima dos interesses dos movimentos sociais e de segmentos da sociedade civil preocupados com as pautas de superação das desigualdades sociais. O que alguns debates da literatura das ciências sociais têm fomentado, de 2015 em diante, é a relevância dessa "nova direita" e o seu potencial, no longo prazo, em termos de representação política. O antipetismo tende a se cruzar com a defesa de políticas de cunho neoliberal, tratando-se de um argumento apresentado por Helcimara Telles (2015a, p. 19), já que

a principal particularidade deste grupo de manifestantes analisados é, além da crítica aos casos de corrupção, o profundo sentimento contrário ao PT, aos seus líderes e às agendas de inclusão social. O que mudou entre 2010 e 2014? Por que apenas presentemente o tema de corrupção passa a alterar as atitudes dos eleitores, a ser associada como um atributo natural do petismo, e a organizar as ruas? Em primeiro lugar, a explicação para os protestos pela saída da presidente e o antipetismo não decorrem somente da cobertura que a mídia faz de casos de corrupção que envolvem o PT. De fato, há parcelas do antipetismo que podem ser explicados como uma reação da opinião pública aos casos de corrupção dos quadros do PT, amplamente divulgados pela mídia. Mas, tal sentimento contrário ao PT não tem sua origem simplesmente na narrativa feita pela mídia sobre os casos de atos ilícitos praticados por este partido [...]. O antipetismo e o antipartidarismo encontrados entre os manifestantes - não procedem simplesmente de uma reação á corrupção. Eles são do mesmo modo provenientes da divergência dos participantes dos protestos com os projetos das políticas de redistribuição de investimentos aos grupos mais pobres.

Esse perfil ideológico corresponde aos resultados obtidos pelas pesquisas sobre os manifestantes antipetistas que foram às ruas em 2015 e 2016. Segundo os dados do Datafolha

\footnotetext{
7 Mais informações da ação no STF da Associação Médica Brasileira (AMB) no link a seguir: https://oglobo. globo.com/brasil/amb-entra-com-acao-no-stf-contra-programa-mais-medicos-9162675 Acesso em 25/ out. 2017
} 
(2015a) sobre o perfil dos manifestantes que foram às ruas no primeiro protesto de 2015 (15/ mar.), 82\% votaram em Aécio Neves nas eleições passadas, 37\% tinham preferência partidária pelo Partido da Social Democracia Brasileira (PSDB), 37\% são assalariados registrados, 74\% foram a uma manifestação pela primeira vez no ano e $76 \%$ dos entrevistados possuíam o ensino superior.

Já o perfil dos manifestantes que foram às ruas nesse mesmo dia, na cidade de Porto Alegre (RS), em pouco se mostra diferente da parcela da população que se mobilizou na capital paulista. Segundo a pesquisa realizada pelo Instituto Index ${ }^{8}, 76 \%$ disseram ter votado no candidato Aécio Neves, $87,2 \%$ se disseram brancos, $40,5 \%$ declararam renda acima de 10 salários mínimos, 44\% disseram estar decepcionados com o PT e 56,8\% afirmaram estar decepcionados com os políticos como um todo. Quando perguntados sobre o que os levou às ruas, 43,8\% afirmaram estar indignados com a corrupção.

Os protestos contra o governo e o PT mantiveram-se ao longo de 2015, nas capitais e nas médias e grandes cidades do País, praticamente unificados sob a perspectiva de denúncia dos petistas pelos suposto envolvimento em atos de corrupção sob a mira da Operação Lava Jato. O perfil dos participantes do protesto de 16 de agosto em São Paulo (cf. Tabela 1) caracteriza um público com maior idade, renda e escolaridade, ou seja, uma classe média paulistana simpatizante do PSDB e antipetista, embora os atos de março, abril e agosto tenham revelado que mais da metade dos participantes não apresentou a preferência por nenhum partido. Vale destacar o peso da participação nestes atos do público acima dos 40 anos, que, de alguma maneira, acompanhou a ascensão de Lula e Dilma à presidência e se constitui de uma indignação com o PT que dificilmente remonta a uma posição política maturada nas úeleições, mas, talvez se caracterize como um posicionamento ideológico maturado no longo prazo em torno de um projeto político consolidado.

\footnotetext{
8 Matéria completa sobre a pesquisa no link a seguir do Jornal Zero Hora: <http://zh.clicrbs.com.br/rs/noticias/ noticia/2015/03/institutos-de-pesquisa-fazem-levantamentos-sobre-o-perfil-dos-manifestantes-em-portoalegre-4719348.html> Acesso 25/out. 2017
} 
Tabela 1 - Perfil dos manifestantes na avenida Paulista. São Paulo (SP), 16 ago. 2015 (em \%)

\begin{tabular}{|c|c|c|c|c|c|}
\hline & & $\begin{array}{c}\text { População } \\
\text { da cidade de } \\
\text { SP } \\
05 / 02 / 2015\end{array}$ & $\begin{array}{l}\text { Av. Paulista } \\
15 / 03 / 2015\end{array}$ & $\begin{array}{l}\text { Av. Paulista } \\
12 / 04 / 2015\end{array}$ & $\begin{array}{c}\text { Av. Paulista } \\
16 / 08 / 2015\end{array}$ \\
\hline \multirow{2}{*}{ SEXO } & Masculino & 47 & 63 & 56 & 61 \\
\hline & Feminino & 53 & 38 & 44 & 39 \\
\hline \multirow{6}{*}{ IDADE } & De 12 a 20 anos & - & 6 & 5 & 5 \\
\hline & De 21 a 25 anos & - & 9 & 6 & 6 \\
\hline & De 26 a 35 anos & - & 28 & 19 & 19 \\
\hline & De 36 a 50 anos & - & 36 & 30 & 30 \\
\hline & 51 anos ou mais & - & 21 & 41 & 40 \\
\hline & MÉDIA & 40,2 & 39,6 & 45,2 & 45,3 \\
\hline \multirow{3}{*}{ ESCOLARIDADE } & Fundamental & 28 & 2 & 3 & 4 \\
\hline & Médio & 44 & 21 & 20 & 20 \\
\hline & Superior & 28 & 76 & 77 & 76 \\
\hline \multirow{3}{*}{ PARTIDO DE PREFERÊNCIA } & Nenhum & 66 & 51 & 56 & 52 \\
\hline & PSDB & 8 & 37 & 32 & 33 \\
\hline & PT & 17 & 1 & 1 & 1 \\
\hline
\end{tabular}

Fonte: DATAFOLHA, 2015b.

É possível afirmar que tais manifestações levaram às ruas milhares de indignados com o governo, o PT e a corrupção diante de um repertório semelhante a 2013, sendo este marcado por um transbordamento societário (BRINGEL, 2013) como uma forma de difusão dos protestos dos setores mais mobilizados para outras partes da sociedade, que se engajaram em redes limitadas de sociabilidade em escala local.

Mesmo que de forma localizada no antipetismo, o ciclo atual de mobilizações parece reafirmar o combate à corrupção como uma possível matriz discursiva nos termos dados por Eder Sader há décadas atrás. Mesmo que possa ser uma perspectiva superficial, aqui observada através deste instrumental analítico, as críticas ao "lulo-petismo" por parte dos manifestantes nunca estiveram circunscritas somente a este grupo político. No protesto de 16 de agosto em São Paulo, o Datafolha (2015b) também avaliou a figura do presidente da Câmara dos Deputados, Eduardo Cunha, do Partido do Movimento Democrático Brasileiro (PMDB) do Rio de Janeiro e do vice-presidente da república, Michel Temer, buscando comparar com a presidenta Dilma Rousseff, como pode ser observado nas Tabelas 2 e 3. 
Conforme os dados obtidos pelo referido instituto, 96\% dos participantes da manifestação afirmaram conhecer Eduardo Cunha e $43 \%$ avaliaram a sua liderança à frente da Câmara como ruim/péssima, o que é quase o dobro dos que avaliaram dessa forma (21\%) entre a população brasileira entrevistada pelo mesmo instituto em junho de 2015. Quanto ao conhecimento do deputado, 35\% afirmaram não o conhecer e, entre os $65 \%$ que afirmaram conhecer, $42 \%$ só ouviram falar sobre o deputado (Tabela 2). Esse dado aponta para o fato de que o brasileiro, de maneira geral, afasta-se do acompanhamento do legislativo e das suas rotinas institucionais, ainda sendo raro o reconhecimento de uma liderança política que esteja à frente do Legislativo. Apesar das configurações próprias do sistema político brasileiro, este fato sustenta como marco analítico o fato de que o Legislativo ainda é visto magicamente como um espaço próprio e dominado pelas lideranças do Poder Executivo, sendo o deputado percebido como um auxiliar do Poder Executivo.

O que também surpreende é a avaliação positiva e regular para 50\% dos entrevistados, que enxergavam no deputado altivez e liderança no combate à (corrupção) presidenta Dilma, marcante na faixa "Somos milhões de Cunha", capturada em um protesto e divulgada amplamente nas redes sociais ${ }^{9}$ como emblema de uma sociedade mobilizada em um combate à corrupção seletivamente estruturado na razão partidária. A força do antipetismo escamoteou, em grande parte da sociedade, o caráter sociológico e complexo da corrupção. O papel "partidário" de veículos de mídia residiu na desestimulação a um debate republicano sobre o assunto, ao passo em que o governo petista se isentou na disputa do problema da corrupção como um desafio ao sistema político como um todo. Faltou aos apoiadores do governo nexos sociais e políticos para a reversão da crise junto àquela classe média chafurdada de críticas aos apoiadores do governo desde o mensalão.

\footnotetext{
9 Interessante ver mais informações e comentários do fato no box dos leitores no link: <https:// blogdomariomagalhaes.blogosfera.vol.com.br/2015/08/21/somos-milhoes-de-cunhas-existe-recall-defaixa/> Acesso em 26/out. 2017
} 
Tabela 2 - Conhecimento e avaliação do deputado Eduardo Cunha (estimulada e única, em \%). São Paulo (SP), 16 ago. 2015

\begin{tabular}{|l|c|c|}
\hline CONHECIMENTO & $\begin{array}{c}\text { Populaçá } \\
\text { brasileira } \\
17 \text { e 18/06/2015 }\end{array}$ & $\begin{array}{c}\text { Av. Paulista } \\
16 / 08 / 2015\end{array}$ \\
\hline CONHECE & 65 & 96 \\
\hline Muito bem & 5 & 45 \\
\hline Um pouco & 17 & 36 \\
\hline Só de ouvir falar & 42 & 15 \\
\hline NÃO CONHECE & 35 & 4 \\
\hline
\end{tabular}

\begin{tabular}{|l|c|c|}
\hline AVALIAÇĀo & $\begin{array}{c}\text { Populaçäo } \\
\text { brasileira } \\
17 \text { e 18/06/2015 }\end{array}$ & $\begin{array}{c}\text { Av. Paulista } \\
16 / 08 / 2015\end{array}$ \\
\hline Ótimo / bom & 13 & 25 \\
\hline Regular & 33 & 25 \\
\hline Ruim / péssimo & 21 & 43 \\
\hline Não sabe & 33 & 7 \\
\hline
\end{tabular}

Fonte: DATAFOLHA, 2015b.

A Tabela 3 avalia o conhecimento da população com relação ao então vice-presidente Michel Temer, sendo que, entre a população brasileira pesquisada em junho de 2015 , 41\% só ouviu falar e $28 \%$ dos que se encontravam na Avenida Paulista, em 16 de agosto, não o conheciam. Entre os manifestantes do dia 16 de agosto, 68\% avaliaram o vice-presidente como ruim/péssimo, o que, em parte, ajuda a explicar a baixa popularidade do atual presidente em todas as pesquisas de opinião divulgadas na imprensa. Apesar da radicalização do antipetismo, tendo como principal indicador a utilização do protesto como repertório, a crise política atual pareceu se expandir ao longo de 2015, atingindo os principais competidores no âmbito partidário. A oposição ao governo da presidente Dilma não significa, a priori, que os cidadãos que foram às ruas apresentam confiança nas instituições e proximidade com os demais partidos. 
Tabela 3 - Conhecimento e avaliação do vice-presidente Michel Temer (estimulada e única, em \%). São Paulo (SP), 16 ago. 2015

\begin{tabular}{|l|c|c|}
\hline CONHECIMENTO & $\begin{array}{c}\text { População } \\
\text { brasileira } \\
17 \text { e 18/06/2015 }\end{array}$ & $\begin{array}{c}\text { Av. Paulista } \\
16 / 08 / 2015\end{array}$ \\
\hline CONHECE & 72 & 100 \\
\hline Muito bem & 10 & 65 \\
\hline Um pouco & 21 & 24 \\
\hline Só de ouvir falar & 41 & 8 \\
\hline NÃO CONHECE & 28 & - \\
\hline
\end{tabular}

\begin{tabular}{|l|c|c|}
\hline AVALIAÇÄO & $\begin{array}{c}\text { População } \\
\text { brasileira } \\
17 \text { e 18/06/2015 }\end{array}$ & $\begin{array}{c}\text { Av. Paulista } \\
16 / 08 / 2015\end{array}$ \\
\hline Ótimo / bom & 13 & 5 \\
\hline Regular & 30 & 22 \\
\hline Ruim / péssimo & 30 & 68 \\
\hline Não sabe & 27 & 5 \\
\hline
\end{tabular}

Fonte: DATAFOLHA, 2015b.

O desfecho do impeachment e das investigações da Lava Jato evidenciaram supostos esquemas de corrupção em quase todos os grandes partidos da arena parlamentar, deixando nítida a estratégia de troca da presidenta Dilma por razões político-partidárias, mas que também tinham como pano de fundo "estancar a sangria" da Lava Jato, dando poder de controle e imunidade parlamentar a uma parte dos envolvidos ${ }^{10}$.

Entende-se, diante dessa conjuntura, que o conceito de projeto político possui um grande potencial para analisar a sociedade civil, sendo definido como um "conjunto de crenças, interesses, concepções de mundo, representações do que deve ser a vida em sociedade, que orientam a ação política dos diferentes sujeitos" (DAGNINO, 2006, p. 282). O que as manifestações de 2015 revelam, na verdade, diz respeito à grande novidade do momento político atual, portanto, além da rearticulação do projeto neoliberal, é a ocupação das ruas como uma forma de ação coletiva, sendo que a sucessão de mobilizações após junho de 2013 reforçou uma guinada conservadora impulsionada pelo antipetismo ${ }^{11}$, tratando-se de

\footnotetext{
10 Ver matéria sobre o fato exposto em processo de delação premiada no ano de 2016: http://www1.folha.uol. com.br/poder/2016/05/1774018-em-dialogos-gravados-juca-fala-em-pacto-para-deter-avanco-da-lava-jato. shtml Acesso em 27/mai. 2016

${ }_{11}$ O Movimento Brasil Livre (MBL) foi um dos grupos que organizaram os protestos realizados contra o PT no ano de 2015, sendo emblemático observar nos documentos, vídeos e site como eles se reconhecem
} 
um pacto conservador (SINGER, 2012) em termos políticos, que mantém as desigualdades no país em um nível de entrecruzamento com os interesses neoliberais e autoritários, vide as expectativas eleitorais (a se concretizar até as eleições de 2018) do deputado federal Jair Bolsonaro (sem partido-RJ) e do Prefeito de São Paulo, João Doria (PSDB), que entrecruzam uma representação política com características de projetos políticos neoliberal e autoritário, nos termos da contribuição de Evelina Dagnino (2006).

Acrise estrutural vivida pelo lulismo tem produzido como um dos efeitos a continuidade do ciclo de protestos a partir de 2013, mobilizando nas ruas uma nova direita, apoiada na participação da sociedade e na intensa militância digital nas redes sociais (TELLES, 2015b). Esta nova direita tem potencializado o confronto com o lulismo em diversas agendas; todavia, a crise do lulismo reside no âmago do projeto democrático-participativo, pois deriva, não somente da mudança dos repertórios de mobilização dos movimentos sociais que, no intuito de evitar o enfrentamento à arbitragem de interesses sustentada pelo lulismo (desmobilização dos trabalhadores), tem recuado dos conflitos mais amplos que envolvem as agendas do governo federal, mas também assiste ao desmonte da inclusão social enquanto uma orientação do governo por meio da defesa do desenvolvimentismo. Em vários momentos, os movimentos sociais parecem assentir à inércia dos partidos de esquerda em reconhecer que somente movimentos sociais e protestos mais contundentes em termos de mobilização podem influenciar uma agenda neoliberal conformada no governo Temer.

As duas denúncias contra o presidente Michel Temer, produzidas pela ProcuradoriaGeral da República (PGR) e negadas pela Câmara dos Deputados, sem nenhum tipo de pressão popular relevante nas grandes cidades, exemplifica o "descaso" dos movimentos sociais e dos partidos de esquerda, em especial, o PT, que tem se mostrado a favor da manutenção de um nível de mobilização a ser preservado em "reserva social" para o momento eleitoral e/ou reformas a serem refutadas pela classe trabalhadora.

Em suma, para Singer (2015, p. 66-67), a crise do lulismo reside em

um Estado capaz de comandar a atividade econômica é de alto interesse para a
fração organizada da classe trabalhadora, assim como para as camadas populares
em geral e também, em um primeiro momento, para a burguesia industrial. A inter-
venção do Estado abre avenida para a industrialização, o pleno emprego, o aumento
dos salários e a inclusão do subproletariado. Só que, logo depois, quando o Estado
passa a ter o poder de comando sobre a economia, os industriais recuam. Em ponto

como defensores de um Estado mínimo, aliando-se, em grande medida, ao receituário neoliberal, mas que utilizaram nas manifestações largamente o slogan "Brasil livre é Brasil sem PT". Página no Facebook da organização: <https://www.facebook.com/mblivre> Acesso em 26/out. 2017 
pequeno, o ensaio desenvolvimentista de Dilma teria, assim, seguido as pegadas da década de 1960. Na partida, a burguesia industrial pede ofensiva estatal contra os interesses estabelecidos, pois depende de política pública que a favoreça. Para isso, alia-se à classe trabalhadora. No segundo ato, os industriais "descobrem" que, dado o passo inicial de apoiar o ativismo estatal, estão às voltas com um poder que não controlam, o qual favorece os adversários de classe, até há pouco aliados. No terceiro episódio, a burguesia industrial volta-se "contra seus próprios interesses" (Cardoso) para evitar o que seria um mal maior: Estado demasiado forte e aliado aos trabalhadores. Une-se, então, ao bloco rentista para interromper a experiência indesejada. Tal como em 1964, as camadas populares não foram mobilizadas para defender o governo quando a burguesia o abandonou. Mais uma vez o mecanismo burguês pendular ficou sem contrapartida dos trabalhadores. A duplicidade recorrente da camada que responde pela vida fabril brasileira faz recordar, por outro lado, que o ensaio desenvolvimentista não foi só voluntarismo. Houve, no início, efetiva pressão burguesa em favor de programa reindustrializante. Mas, ao não lembrar a lição de que o avanço estatal seria sucedido de inevitável recuo, o plano desabou. Em suma, ao cutucar onças, a presidente deveria ter considerado os instrumentos que teria à mão para reagir quando viesse o bote do contra-ataque. Sem planejamento político, o ensaio desenvolvimentista abriu um vácuo sob os próprios pés e acabou por provocar a mais séria crise do lulismo quando a reação burguesa unificada em favor do retorno neoliberal tornou-se incontrastável. Até por não haver, na sociedade, quem enxergasse a necessidade de contrastá-la.

Singer aponta, em uma outra dimensão analítica, o contra-ataque dos setores neoliberais da economia que passaram a agir contra o governo Dilma, patrocinando o impeachment como "medida" política para reorganizar os interesses econômicos a partir das decisões de governo. O que a "nova direita" tem reafirmado, enquanto projeto político, é o imenso valor a algumas pautas típicas do neoliberalismo, o que coaduna com a erosão no apoio das bancadas parlamentares ao governo Dilma, que levou ao avanço e à concretização da admissibilidade do impeachment na Câmara dos Deputados e no Senado Federal. A confirmação de que o impeachment serviria de manobra política, buscando delimitar as ações da Lava Jato que se tornaram evidentes ao país com o vazamento, em maio de 2016, da conversa gravada entre o ex-presidente da Transpetro, Sérgio Machado e o Senador Romero Jucá (PMDB-RR), discutindo formas de "estancar a sangria" da Lava Jato, porém, o áudio foi gravado em março daquele ano, no mesmo mês das ações mais polêmicas da operação como a liberação de um áudio entre a então presidenta e Lula no caso do "termo de posse", que foi depois interpretada como equívoco na opinião pública, reforçando a politização do judiciário.

Uma outra dimensão explicativa do impeachment está ligada a dois aspectos: em um primeiro plano, o golpe parlamentar teve como propósito levar ao Planalto, medidas neoliberais referendadas pelos capitalistas enquanto um ataque aos direitos trabalhistas, privatizações, alteração no sistema de partilha do pré-sal, ao financiamento às universidades públicas, etc. O segundo aspecto do golpe, dado por meio do instituto do impeachment, 
tinha como articulação explícita interferir na Lava Jato. O script do golpe envolveria o caráter de coordenação política das medidas que pudessem levar a uma alteração dos atores institucionais responsáveis pela operação, o que somente seria possível em termos de "poder de veto" a partir do gabinete da Presidência da República. O que viria em seguida, no timing do impeachment com a posse do Presidente Michel Temer, seriam mudanças previstas no marco legal envolvendo cargos como o do Procurador-Geral da República (PGR), membros do TSE, STJ, STF, Ministério da Justiça, Direção Geral da Polícia Federal, etc.

\section{Ciclo de protesto atual: direita e esquerda nas ruas?}

Sidney Tarrow desenvolveu o conceito de ciclo de protesto no intuito de analisar os movimentos sociais em termos de ação coletiva e que são estabelecidos pelo caráter conflitivo, caracterizados por "rápida difusão da ação coletiva dos setores mais mobilizados para os menos mobilizados, passo estimulante de inovações nas formas de disputa, novos frames de ações coletivas (ou retransformados), combinação de formas de participação organizadas e não-organizadas, e sequências de interações intensificadas entre os desafiadores (militantes dos movimentos) e as autoridades, que resultam em reformas, repressão e, algumas vezes, em revoluções (TARROW, 1994, p. 154). Os ciclos de protestos se caracterizam pelo acirramento dos conflitos, não somente nas relações industriais - como afirma a teoria marxista ortodoxa - mas também nas ruas, nas escolas, etc. Eles se difundem dos grandes centros para os pequenos ou áreas rurais periféricas (GOHN, 2004, p. 96). Desse modo, partimos da premissa de que há um ciclo de protesto em andamento, de forte inclinação conservadora nos direitos humanos, e neoliberal em termos econômicos, que merece ampla e sistemática investigação, algo que foge ao propósito deste artigo.

O ciclo de mobilizações desta "nova direita" é um dos componentes da crise política iniciada no governo Dilma e articulada com a oposição partidária ao PT. Conforme matéria de capa da Le Monde Diplomatique Brasil (n. 124), publicada em novembro de 2017, há um terreno pantanoso de influência de atores internacionais por trás destes grupos que articulam, a um só tempo, conservadorismo moral e ideias ultraliberais, sem apontar, explicitamente, que apoiam o governo Temer desde o período de mobilizações a favor do impeachment. Em matéria publicada no UOL, em 27/05/2016, áudios a que o portal tivera acesso mostram que 
os líderes das mobilizações confirmam apoio político e financeiro dos partidos interessados no impeachment:

[...] o MBL (Movimento Brasil Livre), entidade civil criada em 2014 para combater a corrupção e lutar pelo impeachment da presidente Dilma Rousseff (PT), recebeu apoio financeiro, como impressão de panfletos e uso de carros de som, de partidos políticos como o PMDB e o Solidariedade. Quando fundado, o movimento se definia como apartidário e sem ligações financeiras com siglas políticas. Em suas páginas em redes sociais, fazia campanhas permanentes para receber ajuda financeira das pessoas, sem ligação com partidos. Em uma gravação de fevereiro de 2016 a que $o$ UOL teve acesso, Renan Antônio Ferreira dos Santos, um dos três coordenadores nacionais do $\mathrm{MBL}$, diz em mensagem a um colega do $\mathrm{MBL}$ que tinha fechado com partidos políticos para divulgar os protestos do dia 13 de março usando as "máquinas deles também". Renan diz ainda que o MBL seria o único grupo que realmente estava "fazendo a diferença" na luta em favor do impeachment de Dilma Rousseff12.

Uma das pesquisas realizadas com os manifestantes antipetistas apontam para uma "tensão" entre a perspectiva de Estado mínimo e o valor aos direitos humanos, o que abre como desafio à literatura, nesse momento, apresentar mais capacidade analítica em compreender os valores destes atores e de que forma podem vir a se manter nas ruas daqui por diante, mesmo sem a presença do PT no Executivo federal, algo que se confirmou a partir de 2016, com a admissibilidade do processo de impeachment e posterior afastamento definitivo da presidenta Dilma pelo Senado.

Alguns dados sobre este ciclo de protestos são reveladores e foram publicados recentemente por Tatagiba, Trindade e Teixeira (2015, p. 209):

a pesquisa realizada pelos professores Pablo Ortellado e Ester Solano durante o protesto do dia 12 de abril revela que a esmagadora maioria concorda com as seguintes afirmações: "Cotas nas universidades geram mais racismo" (70,90\%) e "O Bolsa Família só financia preguiçoso" (60,40\%). Em outro levantamento, realizado no mesmo dia, ao serem perguntados quais ações do governo afetaram negativamente sua vida: $44,5 \%$ mencionaram o Bolsa Familia, $43,5 \%$ o auxílio reclusão e $35,6 \%$ as cotas raciais nas universidades públicas. Sobre as que afetaram mais positivamente, destaca-se o Prouni com $29 \%$ de aprovação. Contudo, essa crítica às políticas governamentais focalizadas e de reparação parece estar associada a uma defesa da atuação do Estado em outras areas. Na pesquisa realizada no protesto de 16 de agosto, Ortellado, Solano e Nader (2015) identificaram que a maioria (97\%) defende que os serviços de saúde e educação sejam universais e gratuitos e $49 \%$ apoiam total ou parcialmente a tarifa zero para os transportes. Esses dados são intrigantes e abrem todo um novo campo de análise. Provavelmente os manifestantes são contra programas de reparação, mas são favoráveis a políticas universais. Afinal, ou a associação entre a direita e a defesa do Estado mínimo deve ser vista de forma mais nuançada no caso brasileiro; ou é preciso problematizar se que quem está nas ruas contra o governo e contra o PT seja apenas a direita, no sentido mais estrito do termo.

12 Link do áudio e da matéria completa no link: https://noticias.uol.com.br/politica/ultimas-noticias/2016/05/27/ maquina-de-partidos-foi-utilizada-em-atos-pro-impeachment-diz-lider-do-mbl.htm 
O grande desafio analítico colocado atualmente é interpretar o descontentamento da classe média com o lulismo, o que perpassa pela interpretação da relação entre o lulo-petismo e o combate à corrupção como uma matriz discursiva deste ciclo de protestos iniciado em 2013 e que alcançou o ápice em 2015.

Sendo o lulismo compreendido como a política implementada pelo ex-presidente, que atraiu o apoio dos mais pobres ao PT sem entrar em atrito com os mais ricos, a crise política que culminou com o fim do governo petista significou a combinação entre elementos conjunturais e estruturais, tratando-se de questões referentes à governabilidade e à necessidade de realizar reformas no modelo de funcionamento do Estado (ABRÚCIO; TEIXEIRA, 2015). No entanto, vai mais além: o fator (controle da) "Lava Jato" se mantém como a principal chave explicativa do impeachment diante de evidências que, a cada momento, se apresentam, de forma mais nítida, nas investigações em curso pela Lava Jato, cujo andamento também refuta a versão "estilizada" do PT e de demais militantes e analistas políticos da esquerda, que enxergam nas investigações um mero recurso político-jurídico de perseguição ao partido. Mas, vale ressaltar que, no âmbito do impacto político, o maior "golpe" funcional a soprar ventos a favor do processo do impeachment veio da divulgação ilegal do áudio por parte do Juiz Sérgio Moro sobre o termo de posse de Lula $(16 / 03 / 2016)^{13}$. Naquele momento, o governo petista buscava uma refundação da sua governabilidade, creditando este papel ao ex-presidente petista, que tinha como objetivo reverter a fuga da base partidária no Congresso, que enxergava na presidenta uma repleta incapacidade de coordenar um "freio" à Lava Jato e de recuperar a economia a curto prazo. Fora um fator "sobrenatural", é razoável supor que, a partir da liderança política do ex-presidente, haveria a probabilidade de se alcançar o número suficiente de 172 votos para derrotar a denúncia do impeachment na Câmara dos Deputados.

A aproximação aqui analisada entre as manifestações de junho de 2013 e os protestos de 2015 tem como ponto forte, em termos de fenômeno, a crítica ao sistema político, balizada na desconfiança nas instituições, porém, há uma característica marcante destas mobilizações: a radicalização do antipetismo tem bloqueado a consecução de um movimento mais ampliado, capaz de conduzir como pauta uma refundação democrática enquanto janela de oportunidade da crise instaurada, o que ajuda a pensar que, paradoxalmente, depois do impeachment o aprofundamento das investigações da Lava Jato (delações da Odebrecht,

${ }_{13}$ Matéria completa no link: http://g1.globo.com/pr/parana/noticia/2016/03/pf-libera-documento-que-mostraligacao-entre-lula-e-dilma.html Acesso em 26/out. 2017 
da JBS, "bunker" de Geddel, etc.) passou a conviver com o "silêncio" das ruas e a esquerda passou a utilizar um repertório confrontacional de crítica às políticas do governo Temer, sem capitanear o tema da corrupção, reconhecendo tacitamente tratar-se de uma pauta mobilizadora da direita, como foi o que ocorrera nos anos de 2015 e 2016. Mesmo assim, a esquerda pareceu recuar na luta contra o governo Temer, quando comparado ao volume de mobilizações ainda no período de resistência ao impeachment.

A movimentação feita por outros partidos de esquerda envolve a leitura de que há um anseio, atualmente, por novas lideranças na política brasileira e, no caso da esquerda, há um entendimento de que será necessário uma transição para o pós-lulismo, já que caberá à esquerda influir no processo eleitoral em defesa de uma representação de interesses que tensione os níveis de conciliação de classe, diferente do que foi feito nos governos Lula e Dilma.

O que pouco tem sido entendido pelas lideranças petistas é que há um conjunto de conflitos sociais colocados no chão da sociedade que não serão sanados com um acordo eleitoral. Portanto, como já foi dito anteriormente, há um componente da crise política brasileira que ultrapassa as eleições de 2018. As realidades resultantes das desigualdades e os seus embates cotidianos, inclusive com forças autoritárias e a militância antidemocrática, nos leva a uma necessidade de empoderar a sociedade civil a criar uma refundação societária que envolva uma nova forma dos partidos políticos de esquerda a lidarem com os movimentos sociais. Diferente de tratar os movimentos como meros "repositórios" de força eleitoral, será crucial uma nova configuração dos partidos, colocando no centro da sua organização a presença na sociedade civil e nas suas respectivas lutas sociais.

\section{Algumas considerações finais}

Ronda este artigo uma incerteza sobre o caminho da democracia no Brasil neste momento político atual, caso seja analisada, sobretudo, pelas lentes da ciência política hegemônica de base teórico-analítica institucionalista. A democracia brasileira parece ter mantido, desde a redemocratização, uma considerável fragilidade em termos de pensamento político e cultura cívica. Talvez, uma agenda sobre a conjuntura política, aberta neste cenário de crise, diga respeito ao colapso republicano das instituições políticas, o que abre espaço para o flerte considerável com desvios autoritários, conhecidos da nossa história, agora encarnada, em especial, na pré-candidatura presidencial do deputado Jair Bolsonaro (Sem 
partido/RJ), reafirmando um projeto autoritário de rebatimento e forte mobilização na sociedade civil, pouco significando uma mera aventura eleitoral ${ }^{14}$. Propostas programáticas de constrangimento às bases dos direitos humanos consolidados no contexto da Carta Magna de 1988 ultrapassam o antipetismo, mas se revela uma onda autoritária, mobilizada e presente em ambientes de institucionalidade da arena estatal, gerando tensão com os valores democráticos e liberais, vide a cruzada moralista de "combate" à ideologia de gênero, partidarização das escolas, "pedofilia" em eventos de arte (nudez), etc.

Desse modo, os protestos antipetistas de 2015 consolidaram, na conjuntura atual, a crise do lulismo, o que não é um decreto de falência política. As pesquisas de opinião apontam, de forma consensual, para uma liderança consolidada do ex-presidente Lula nas intenções de voto de cunho programático e de forte representação política, o que pode levar a uma transferência de votos, em caso de impedimento jurídico da sua candidatura, em virtude da sua iminente condenação, em segunda instância, dentro das investigações provenientes da Lava Jato.

A novidade esboçada neste trabalho parte da observação empírica de um consequente avanço do projeto político neoliberal ${ }^{15}$, baseando-se nos termos analisados por Evelina Dagnino. As jornadas de junho de 2013 e as manifestações contra o governo articularam forças sociais contrárias às políticas igualitaristas representadas pelo PT e demais partidos de centro-esquerda, na medida em que se reduziam a uma visão gerencial e "consumidora" do Estado. Outra novidade marcante é o fato de os grupos e partidos de direita utilizarem repertório de mobilização em forma de protesto semelhante aos movimentos sociais orientados ideologicamente pela esquerda nas últimas décadas, o que atesta o sentido de radicalização do antipetismo.

Um outro indicador conjuntural aqui decantado: o resultado eleitoral das eleições municipais de 2016 pautou-se em um caráter plebiscitário das candidaturas antipetistas nas grandes e médias cidades, levando parte do eleitorado para o leito da "nacionalização" das eleições locais. A democracia brasileira entra em uma fase de ebulição e tensões na relação entre Estado e sociedade civil, que não se limita ao desenho das instituições e da competição

\footnotetext{
${ }_{14}$ Pesquisa divulgada pelo IBOPE no dia 29/10 aponta o deputado carioca em segundo lugar na intenção de votos. Alguns dados da pesquisa podem ser acessados no blog de Lauro Jardim (O Globo): <http://blogs. oglobo.globo.com/lauro-jardim/post/ibope-lula-e-bolsonaro-na-frente.html> Acesso em 29/out. 2017

15 Como recurso de diálogo com a autora, vale a leitura do manifesto do PMDB, "Uma ponte para o futuro" (2015), que inspirou as decisões do governo liderado pelo novo presidente Michel Temer, substituindo a presidenta Dilma Rousseff.
} 
eleitoral, mas interfere na disputa do "espírito" do poder democrático, para além do embate eleitoral e partidário. As mobilizações de grupos organizados deixarão em aberto o ciclo de protestos atual que tem posto direita e esquerda nas ruas.

\section{Referências}

ABRUCIO, F.; TEIXEIRA, M. A. C. Combinação de duas crises aumenta a incerteza atual. GVexecutivo, São Paulo, vl. 14, n. 2, jul.-dez. 2015.

BRINGEL, B. Miopias, sentidos e tendências do levante brasileiro de 2013. Insight Inteligência, Rio de Janeiro, a. XVI, n. 62, p. 42-51, jul.-ago.-set. 2013.

DAGNINO, E. Sociedade civil e espaços públicos. Rio de Janeiro: Paz e Terra, 2002.

DAGNINO, E.; OLVERA, A. J.; PANFICHI, A. (Org.) A disputa pela construção democrática na América Latina. São Paulo: Paz e Terra, 2006.

DATAFOLHA. Manifestação na avenida Paulista. 17 mar. 2015a. Disponível em: < http:// media.folha.uol.com.br/datafolha/2015/03/17/manifestacao-15-03.pdf >. Acesso em: 30 mar. 2016.

DATAFOLHA. Manifestação na avenida Paulista. 16 ago. 2015b. Disponível em: <http:// media.folha.vol.com.br/datafolha/2015/08/17/manifestacao-16-08.pdf>. Acesso em: 30 mar. 2016.

EL PAÍS. Singer: "A democracia vai pagar um preço alto se o impeachment vingar". São Paulo, 11 out. 2015. Disponível em: <http://brasil.elpais.com/brasil/2015/10/10/ politica/1444431979 853273.html> Acesso 11/out. 2015.

ESPIÑEIRA, M. V.; MATHEUS, D. O mosaico das contestações recentes no Brasil (20132015): vozes difusas e inimigos diversos. In: SOUZA, C. A.; BARREIROS NETO, J. (Org.). \#democraciabr: o momento político atual. Salvador: Faculdade Baiana de Direito, 2015. p. 147-168.

LEITE, Daniel. Aécio Neves diz que Dilma não tem condições morais de pleitear segundo mandato. O Globo, 13 set. 2014. Disponível em: <http://oglobo.globo.com/brasil/aecioneves-diz-que-dilma-nao-tem-condicoes-morais-de-pleitear-segundo-mandato-13927985>. Acesso em: 27 mar. 2015

PRAGMATISMO POLÍTICO. Avaliação da presidente Dilma Roussef. mar. 2015. Disponível em: <http://www.pragmatismopolitico.com.br/wp-content/uploads/2015/03/ dilma-datafolha.jpg>. Acesso em: 30 mar. 2016.

RIBEIRO, Renato Janine. O Brasil e a democracia de protesto. Revista Matrizes, v. 8, n. 1, p. $93-118,2014$. 
ROMÃO, W. M. \#naovaitercopa: manifestações, Copa do Mundo e as eleições de 2014. Agenda Política, São Carlos, v. 1, n. 2, p. 152-167, 2013.

ROMÃO, W. M. Entre a construção da democracia e a política em risco: sociedade civil e manifestações no Brasil recente. In: SOUZA, C. A.; BARREIROS NETO, J. (Org.). \#democraciabr: o momento político atual. Salvador: Faculdade Baiana de Direito, 2015. p. 181-190.

SINGER, A. Os sentidos do lulismo: reforma gradual e pacto conservador. São Paulo: Companhia das Letras, 2012.

. Cutucando onças com varas curtas. Novos Estudos Cebrap, São Paulo, n. 102, p. $39-67,2015$.

TATAGIBA, L.; TRINDADE, T.; TEIXEIRA, A. C. C. Protestos à direita no Brasil (2007-2015). In: CRUZ, S. V.; KAISEL, A. CODAS, G. (Org.). Direita volver. o retorno da direita e o ciclo político brasileiro. São Paulo: Fundação Perseu Abramo, 2015. p. 197-212.

TELLES, H. Corrupção, legitimidade democrática e protestos: o boom da direita na política nacional? Interesse Nacional, São Paulo, a. 8, n. 30, p. 28-46, jul.-set. 2015 a.

TELLES, H. Corrupção, antipetismo e nova direita: elementos da crise político-institucional. GVexecutivo, São Paulo, v. 14, n. 2, p. 36-39, jul.-dez. 2015 b.

UMA PONTE para o futuro. Brasília, 29 out. 2015. Disponível em: <http://pmdb.org.br/wpcontent/uploads/2015/10/RELEASE-TEMER A4-28.10.15-Online.pdf> Acesso em 20 abr. 2016.

\section{ABSTRACT}

This work has the purpose of stimulating the conjunctural debate on the Brazilian politics, considering the existence of a crisis of the lulismo as phenomenon of political representation that culminated with the impeachment of the president Dilma Rousseff (PT) in August of 2016, from several factors internships carried out as backroom articulations within institutions and external factors through the realization of a set of mobilizations of social segments of higher income and schooling of the great Brazilian cities, leading to wider consequences than the outcome of impeachment before a corporate activism that tends to generate long-term impacts. Thus, it is sought to present the concept of protest cycle as an analytical tool to interpret a "conservative turn" in Brazilian civil society around a neoliberal political project of great consequence for the democratic construction in the country. Different from the institutional analysis prevailing in political science, the objective of this article lies in the approach to the perspective of understanding democracy beyond the electoral environment.

Keywords: lulism; protest; conjuncture. 